\title{
Brief Exploration on Art Feature of Zhuxian Town New Year Woodcuts
}

\author{
Hui Li \\ School of Art and Design \\ Huanghe Science and Technology College \\ Zhengzhou, China 450063
}

\begin{abstract}
This paper conducts research on art feature, aesthetic feeling of colors, sculpting language feature, mode of composition and stylistic form of Zhuxian Town New Year Woodcuts based on organizing their history and current situation. Then the excellent folk culture heritage has been further recognized, which has significant meaning to fully make their social and economic value known.
\end{abstract}

Keywords-art features; aesthetic taste; image; folk

\section{INTRODUCTION}

The art feature of Zhuxian Town New Year Woodcuts is a pattern of manifestation of image. That what the pictures' images themselves represent is associated with folk's conception before the images come into art works. The images enjoy some implication and connotation and possess certain effect and meaning. To establish the effect and meaning, as a symbol with special significance as early as the images are chosen as a structure of works, reflect the feeling of works' subject thought on visual expression. ${ }^{1}$ That is to say, the creative content of the pictures is related to people's conception, which reflects certain relationship between human and nature and social. The perceptual image of the pictures has certain inheritance, continuity and collectivity. When accepting this kind of art form of the pictures, people put their own perspectives and realistic feelings together to appreciate the pictures. Therefore, in plastic arts the pictures own an image with symbolic meaning. 2

\section{AESTHETIC FEELING OF COLORS OF ZHU XIAN COUNTY NEW YeAR WOODCUTS}

Zhu Xian County is the earliest birthplace of New Year pictures. Artists apply traditional method into confecting colors. The colors of the pictures are strong and solemn, bright and transparent without fading enduring long term.

Black color: firstly mix pine soot plus flour, strong tea water into batter, then let them ferment, next add some water and use graphite to grind the mixture. The artist names the mixture "Guai Shui grinding". When using it, we should add some vulcanized rubber water. If we would like to print eyes,

\footnotetext{
${ }^{1}$ Wang Shucun \& Wang Haixia. New Years Paintings. Zhejiang People's Publishing House. Mar. 2005. the 1st edition: 39.
}

eyebrows and mustache, colors printed on paper could be pitch-black with an appropriate amount of rock candies and tea water into the mixture.

Yellow color: firstly stir-fry sophora flower bud (Chinese scholar tree bud) and lime in iron wok until they become charred, then add alum, and put all of them into a big wok to boil over one hour until the mixture shows yellow color. The color shows aplomb and a lingering charm. Some shops choose another way to add water into aura mine, and then add vulcanized rubber, put cooking starch to boil the mixture. The color shows delicate and enduring.

Danhong: pulverize Guangdan and add some water, put them into a big crock, stir the sediment impurity. The whole process needs six crocks to stir the sediment and get the floating things by turn until the mixture's color is pure, and then add vulcanized rubber to finish. The jargon calls the process "floating Guangdan". The color does not change in a long term. If we use acid orange to boil, the color will be bright as well.

Sunflower-purple: to boil sunflower, alum, vulcanized rubber and water can make it.

Bitter green: add water and gelatin into aerugo produced by oxidized scrap copper, and to boil the mixture can make it.

Cerise: add water and glue into alkaline second red essence, and then to boil the mixture can make it.

Azurite: to boil azurite powder and glue with water can make it.

Gold dust: to mix fish bone powder (cuttlefish bone) and gold dust and stir the mixture evenly can make it. The feature is the mixture shows golden yellow and glittering with fluorescence.

Scattered gold: to make gold-plating foil fragments, and then put the fragments in a special canister, scatter them evenly and make them seep. The scattered gold can be furnished on clothes, showing magnificence. ${ }^{2}$

\footnotetext{
${ }^{2}$ The New-Year paintings production process flow of Zhuxian Town New-Year Woodcuts House.

Dan Zhicun. Central Plains Crafts and Folk Art. Henan People's Publishing House. Apr. 2006. the 1st edition: 242.
} 
Main colors of Zhuxian Town New Year Woodcuts are green, red, white and black which are consistent with the traditional "five colors". The deep implication of the traditional "five colors" contains "five elements" gold, wood, water, fire and earth which represent life's continuity and prosperity and family's booming. The application of "five colors" in Zhuxian Town New Year Woodcuts implies blessing and praying for much longer life. ${ }^{3}$ This kind of colors' expression is still applying in current works.

Compared with other regions' folk New Year pictures, the Zhuxian Town New Year Woodcuts have a unique feature which excludes blue. In terms of five-color atheistic appreciation, the pictures deal with the colors according fiveelement theory, i.e. taking purple and green as preference. In color matching, the pictures take red, yellow, purple, green and black as main colors, with the original white color of the paper. The purple and green represent blue, and the purple can be categorized as black as well. Therefore, the picture plane remains consistent with the five-number auspicious value and five-number worshiping ancient customs in the traditional five-color aesthetic appreciation. Facial features in the pictures are rare applied much colors, in most cases showing white color, apart from the immortals and saints imitating theatrical masks in the divine description. There are only lips and eyelids touched with red color, which means the white of the paper is used as one color.

The preference of Zhuxian Town New Year Woodcuts can account for three reasons: first, since Zhou dynasty, the five-color has begun to worship the five-element theory, and then the five-color divides into two parts of yin and yang with yin representing burial and yang representing auspiciousness. The pictures belong to the yang category. Folk's five-color view of aesthetic appreciation can not abandon yin colors from the mixed color, but the yin colors are not conform to the auspicious atmosphere. Folk painters adopt the color-preference measure of mutual promotion and restraint in the five elements to tackle with this contradiction, replacing black with purple and replacing blue with green. And even when drawing the general body, artists will not print the chalk line pure black, which turns the yin-color black to yang-trend neutral color, i.e. dark grey form "gold (white) generates water (black)"; second, Zhuxian Town New Year Woodcuts derive from Song dynasty. For some government taboo reasons, the blue and white were forbidden, resulting in color-preference disposal of blue in folk's five-color aesthetic appreciation view; third, in Jing and Yuan dynasties, the governors of the ethnic groups believed in Shamanism, worshiping blue and white. For one thing, folk were forbidden to use governors' color preference, for another, national sentiment exerted some influence on the color-preference to deal with the blue color. ${ }^{4}$

In specific use of colors, different people enjoy different preferences of color, customers and habits and aesthetic

\footnotetext{
${ }^{3}$ Pan Lusheng \& Tang Jialu. Introduction to Folk Art. Shandong Education Publishing House. Oct. 2002 the 1st edition: 151.

${ }^{4}$ Pan Lusheng \& Tang Jialu. Introduction to Folk Art. Shandong Education Publishing House. Oct. 2002. The 1st edition: 156-162.
}

tastes. Such as Wuqiang New Year pictures do not use purple, which is because the local people have a customer of hating purple; the big painting shops of Yangliuqing New Year pictures have a taboo of using original colors, for local people have a unique aesthetic taste. Through simple comparison, it can be concluded that Zhuxian Town New Year Woodcuts are different form other counterparts, but the essence of color expression are consistent, showing different shapes and colors. With function of decoration, the pictures are full of romantic atmosphere.

\section{SCUlPTing LANGUAGE FEATURE OF ZHUXIAN TOWN NEW YEAR WOODCUTS}

From painting tigers and guardian gods on gate in Han dynasty, divine roosters on gate in Wei and Jin dynasties to Buddhist text version paintings in Sui and Tang dynasties, Zhuxian Town New Year Woodcuts experienced the above developmental stages, which becomes the foundation of Song dynasty's New Year Woodcuts.

The Character shape of Zhuxian Town New Year Woodcuts is of primitive simplicity, solemn, dignified and unaffected. The pictures are not only praised highly by arts circle, but also popularized by folks. The principle of character shape follow ancient people's intention conception, not asking for similarity in form, but for similarity in spirit. For instance, standing-stance gods in the pictures are often an indomitable spirit with power and grandeur. The proportion of gods' shapes is not normal, but romantic and exaggerating. Head of the feature accounts for one third of full body and the whole shape is focusing on depicting the head and face. Although the figure is strong and sturdy, their horses are very small. Seeing figures facial expression, you can know his character and spirit. This kind of expression way strengthens the charisma of figures from different aspects. In figure's motion shape, artists learn and absorb figure shapes from opera stage. Military officers in Opera often make a stage pose with chest out, holding spear and riding on horse, shrugging shoulders and swinging legs, horse-stance and bending legs. All of the stances are shown in the military officer's divine guardians' image. Figure's line is relatively rough with strong curves, showing dynamic rhythm. There are ying (thick) and yang (thin) lines, forming a strong comparison between the ying and yang, especially in the garments' texture of the guardians, showing strong local specialties. In the square face of the guardians mostly shows big-flat powerful eyebrows, round-opened eyeballs and flowing whiskers, which represents persons' majestic looking and righteousness. The image can give us the feeling of elegance, sturdiness and vigor. If you appreciate the pictures carefully, you can find the blade point of pictures is sharp and tough, curving and smoothing, just like what Chinese calligraphy's and traditional Chinese painting's strokes require. The strokes can give us energetic and strong feeling with layers of heavy and light aesthetics. ${ }^{5}$

Character shape of Zhuxian Town New Year Woodcuts is different from Chinese traditional paintings, nor the

${ }^{5}$ Dang Zhichun. Centeral Pains crafts and folk art. Henan People's Publishing House. Apr. 2006. The 1st Edition: 243 
western painting conception. The shape belongs to subject impressionism, with a nature of exaggeration and deformation, generalization and revealing by spirit. To the character's important parts, the pictures often strive to express them from front face, such as guardian faces. The side face is rare shown and the reverse side is little shown. From the general effectiveness of character shape, the subject color is strong and the image is of exaggeration and deformation. The image will not depict according to the real structure. Although lacing of the realistic feeling of natural image, the pictures pay more attention to the similarity in spirit. Thus, the pictures attain to the truth of art.

As the development and expanding of Zhuxian Town New Year Woodcuts, there emerges many kinds of guardians and the categories become more detailed, such as evilavoided guardians, blessing-praying guardians, financeprotection guardians, three-star guardians and praying-forpregnancy guardians. In general, the guardians are divided into two categories, military guardians and civilian ones. Through comparison we can conclude that the pictures maintain many early time's shape features. In most cases, the features are embodied in the exaggerating looks, gesture, and expression. Thus, the shape is sturdy, of primitive simplicity and the lines are rough, strong and straight. But in the civilian guardians from the pictures, we can find out the distinct difference from military ones, such as images from blessing-praying guardians and three-star guardians who are much closer to people's image in reality. The feeling of civilian ones are the appearance is elegant and graceful, the looks are amiable and genial. The gesture of the civilian ones is not that exaggerating as military ones. The exaggerating deformation of the civilian ones is not that strong. Although the form has changed, in fact it reflects people are praying for auspiciousness and harmony. Thus, the civilian guardians share the same shape conception with military ones.

\section{The Composition Mode of ZhuXian Town New YEAR WOODCUTS}

Composition of Zhuxian Town New Year Woodcuts inherits traditional composition method. The whole picture is fully-embodied, compact, precise, blank above and prominent below, leaving smaller area of blank. In the arrangement of figures with a distinction, the significant figures have bigger shapes and the minor ones smaller shapes. And there are primary and secondary parts in the pictures with vivid images. With the smart arrangement of the scene, the pictures strive to express aesthetics of symmetry. Although the emphasis of the composition is figure, selection of background and props share the same importance. The background and props function as decoration. In the pictures, figures and props, facial expressions and garments are well arranged with density at intervals. A couple guardians often adopt exaggerating gesture with total matching and some minor parts using different way to depict, which indicates an effectiveness of decoration. There are a random in selection and arrangement of images. All of the images are serving theme. Sometimes the content will decide the composition, showing the subjectivity. The pictures' images derive from real life, but not simply imitate. They have experienced long-term sorting out, generalizing, selection, processing and refining by rightists.

The variety of contents of Zhuxian Town New Year pictures decides their composition. Then there are many composition modes. That is to say the composition of the pictures considers the same factor the sculpting and color should take account into. The sculpting, composition and color take the same principle of subjective image. The principle is consistent with composition theory of New Year pictures around China, which reflects people's praying-forblessing mind and recognition conception.

\section{STYLISTIC FORM OF ZHUXIAN TOWN NEW YEAR WOODCUTS}

For a long time, most of the New Year picture artists from Zhuxian Town have not received professional artistic training. To express their emotion and life requirement, they are free to create different styles of the pictures without any limitation of art standards. Such styles have sense of "let it go". Although some works are shown naïve and rough, inconsistent with art "convention", the works are not affected, showing simplicity and frankness and the works themselves beauty of simplicity. The pictures, from content to form, express a love for life, pursuit for dream, praying for happiness through which the pictures embody an optimistic and progressing spirit. The positive spirit develops Chinese nation's characters and ethnic look.

In creative attitude, when artists create the New Year pictures in early time, they placed personal internal dream and intention in the works. By doing this, the pictures are infused into utilitarianism, voicing people themselves sentiment. The New year pictures, like this kind of art form, are not limited to a large extend. The pictures come along as life and folk custom develop. Then, the pictures not only absorb the essence from Chinese traditional royal court art, but also have the characters of original culture. Aside from this, the pictures themselves have nature of entertainment, which is different from other styles of arts, for the pictures themselves are for satisfying people's requirement of selfproduction, life and spirit. Though nowadays some artistic creation are to achieve understanding and resonance from appreciators, or to transmit some information, and more or less have some self-entertainment nature, most of them are shown in the creation, whereas, the result shows much utilitarianism. ${ }^{6}$

From the creation materials of Zhuxian Town New Year Woodcuts, most of the materials are cheap and plain natural things which can be seen everywhere. The appearance looks rough and is not beautiful. But after smart processing, the natural and simple mode of the pictures is shown to us perfectly. Although the pictures appear some roughness and rustic taste, they bring us extensiveness frankness but not roughness and coarseness. In fact, roughness and simplicity

${ }^{6}$ Deng Fuxing. Introduction to Chinese Folk Arts. Heilongjiang Publishing House, Mar.2003. the 11th edition: 171-172. 
are not absolute. Roughness does not mean simplicity and vice versa. In person, the so-called "rustic taste" of the pictures, in fact, is the natural artistic individuality and where the charm is. The goodness represents Chinese nation's frankness he simplicity. Being simple often reflects people's spiritual character, so does the simplicity of creation materials. $^{7}$

\section{CONCLUSION}

Forthright, sincere and random creative conception is related to people's art thinking, expression way and aesthetic taste, but is not only immature, clumsy and weird from appearance. The art creation of New Year picture transfers subjective mental activity into practical activity. The being of reality, to a large extent, is restrained by creative concept. Through several hundreds years, folk artisans of Zhuxian Town New Year Woodcuts, to certain degree, have not received too much interference and restraint. They only have enthusiasm of life's attitude and aspire after good life with some romantic imagination and exaggeration. Therefore, we can see some subjective and self-conceited structures which make sense but not reasonable in the pictures. The young artisans have simple and natural creative thinking, so the creation process does not need too much external factors and contents. Completeness and simplicity are enough to express what the artisans intend to say in the heart. That is whey the art form of their works is simple, forthright and sincere. To summarize, the Zhuxian Town New Year Woodcuts render us easy-understanding, popularization and amiable feelings. Neither abstruse is the pictures, nor is obscure. The pictures are plain, but not short of splendor.

\section{REFERENCES}

[1] Wang Shucun, The Development History of Chinese New Year. Beijing Arts and Crafts Press, Jan. 2006.

[2] Dang Zhicun. Central Plains Crafts and Folk Art. Henan People's Publishing House, Apr. 2006.

[3] Wang Shucun. Summary Discussion on Chinese New Year Art. on Kaifeng's Art. Popular Literature Publishing House, 2003.1

[4] Shen Hong. Zhuxian Town New Year Woodcuts. China Pictorial Publishing House, Jan. 2006.

[5] Feng Jicai Chinese New-Year Woodcuts Album - Zhuxianzhen volume. Zhonghua Publishing House, Oct.2006.

[6] Dai Songcheng. Seven-Day Discussion on Zhuxianzhen New Year Woodcuts. Zhongzhou Ancient Books Publishing House, Jan.2006.

[7] Ni Baocheng. Study on Zhuxian Town Woodcuts. On Kaifeng's Art. Popular Literature Publishing House, 2003.1

[8] Pan Lusheng \& Tang Jialu. Introduction to Folk Art. Shandong Education Press, Oct. 2002.

[9] Deng Fuxing. Introduction to Chinese Folk Arts. Heilongjiang Publishing House, Mar.2003.

\footnotetext{
${ }^{7}$ Deng Fuxing. Introduction to Chinese Folk Arts. Heilongjiang Publishing House, March 2003. the 11 th edition: 172.
} 